May 30, 2003

Economies of Scale in Wastewater Treatment and Planning for Urban Growth

\author{
Lewis D. Hopkins \\ Department of Urban and Regional Planning \\ University of Illinois at Urbana-Champaign \\ 111 Buell Hall, 611 Taft Drive, Champaign, IL 61820 USA \\ L-Hopkins@UIUC.edu
}

Xiaohuan $\mathrm{Xu}$ and Gerrit J. Knaap,

National Center for Smart Growth

University of Maryland

0111 Caroline Hall, College Park, MD 20742 USA

Acknowledgments. This paper is based on work supported by the National Science Foundation under Award Number SES9816816. Any opinions, findings, and conclusions or recommendations expressed in this publication are those of the authors and do not necessarily reflect the views of the National Science Foundation. Keith Brouhle and Yan Song collected and organized much of the data for this analysis. Alex Anas provided useful suggestions during the course of this work and Elizabeth Holler provided useful editorial suggestions. 


\section{Economies of Scale in Wastewater Treatment and Planning for Urban Growth:}

Abstract. Can urban growth patterns take advantage of economies of scale in infrastructure by relying on fewer and larger treatment plants? Estimates of potential cost savings from alternative wastewater treatment consolidation strategies for the metropolitan Chicago region suggest that the timing of consolidation is important. Carefully timed consolidation, even consolidation that occurs after development has occurred, might yield present value savings on the order of $\$ 170$ million in capital costs. These potential savings are large enough that such strategies should be considered when planning for metropolitan growth.

The Chicago metropolitan region has over 100 wastewater treatment plants, many of them very small. What advantages might accrue if these plants were consolidated over time into fewer and larger plants as the metropolitan area continues to grow? What patterns of urban growth would be efficient with respect to capacity expansion, consolidation, and replacement strategies? This case is one instance of the more general question: Are cost savings from growth patterns that take advantage of economies of scale in infrastructure sufficient to justify the costs of plans, incentives, and regulations necessary to achieve such patterns?

The relationships between land development and infrastructure provision are fundamental to plans for urban development (Kaiser, Godschalk, and Chapin, 1995; Hopkins, 2001b; Hopkins, 2001a; Knaap, Ding, and Hopkins, 2001). The empirical 
literature focuses on costs related to development density and to dispersal of subdivisions served by a single wastewater treatment plant (Bahl, 1963; Windsor, 1979; Peiser, 1984; Burchell, Shad, Listokin et al., 1998; Speir and Stephenson, 2002). There is little empirical literature, however, addressing costs related to the number, sizes, and timing of treatment plants for a large metropolitan area and whether urban development uses available capacity before new capacity is added at other locations.

In this paper we estimate potential cost savings from alternative wastewater treatment consolidation strategies for the metropolitan Chicago region. Our results suggest that the timing of consolidation is important. Carefully timed consolidation, even consolidation that occurs after development reaches buildout, might yield present value savings on the order of $\$ 170$ million in capital costs. These potential savings are large enough that such strategies are worth investigating in more detail when developing alternatives for particular urban development plans.

\section{Infrastructure and efficient urban growth}

Wastewater treatment systems consist of collector sewers, interceptor sewers, and treatment plants. Collector sewers bring wastewater from individual buildings to large sewers, called interceptors because they originally intercepted the flow from small pipes before it entered lakes or rivers. Interceptors convey wastewater to a treatment plant that

removes waste and releases cleaner water into a lake or river. Sewers are most efficient if they rely on gravity flow, and thus sewer networks generally follow natural drainage patterns in order to flow downhill. 
Focusing on wastewater treatment systems alone, it is, in principle, efficient to build one treatment plant of appropriate size with respect to economies of scale of treatment, collection, and timing of development and then develop land as rapidly as demand warrants until all of the plant capacity is absorbed. Then, build another treatment plant and repeat the process. This basic idea was the principle used to establish the Urban Service Area in Lexington, Kentucky (Segoe and Associates, 1958). The logic of this strategy occurs at other scales as well. Each interceptor sewer should be fully utilized before others are built, and each collector sewer should be used before others are built. This strategy would result in urban development occurring in a hierarchy of "chunks" of different sizes: the service areas of collector sewers, the service areas of interceptors, and the service areas of treatment plants.

Real situations are more complex for several reasons. One, there are many different types of infrastructure — schools, parks, fire stations, water supply—with different economies of scale and different spatial patterns (Frank and Fulconer, 1990). Growth patterns should respond to the combinations of these, not just the wastewater treatment system. Two, growth occurs from an existing situation, which includes existing infrastructure, land use, ownership, and jurisdiction patterns. In this case study, we set aside the complexity of multiple types of infrastructure, but we address the potential gains when evolving from existing patterns as growth occurs. Although we analyze metropolitan Chicago, our purpose is to estimate the approximate magnitude of potential savings for a large metropolitan region, not to consider specific alternatives for the Chicago Metropolitan area. The results indicate the types of strategies and policies that 
should be considered, for which more detailed and situation specific analyses should be undertaken before making recommendations for specific instances.

Optimal strategies for efficient expansion of infrastructure capacity are extremely difficult to define, much less to identify through computation (Freidenfelds, 1981; Chang, Brill, and Hopkins, 1982). We make no attempt to do so. Instead, we identify three scenarios that span a range of possible expansion strategies. After running a simulation to determine when, where, and how much expansion would occur in each scenario, we compute the capital and operating costs.

In order to evaluate consolidation of treatment plants, the tradeoff between lower costs from economies of scale of larger treatment plants and higher costs from the larger and longer interceptors needed to bring wastewater from a larger area to these plants must be considered (Chang, Brill, and Hopkins, 1982). We can ignore the costs of collector sewers because they will be of the same total length and size regardless of the degree of consolidation of treatment plants. It is sufficient to consider only the interceptors necessary to consolidate from existing treatment plants by piping wastewater from locations of existing plants to locations of consolidated plants.

The paper is organized as follows. First, we describe the framework of analysis, the data, and their limitations. Second, we explain the calculations for each scenario. Third, we compare the scenarios. Fourth, we consider sensitivity of the results to uncertainty and data error. Finally, we interpret the implications of these results for metropolitan development planning. 


\section{Framework and Data}

The problem is framed at a regional level based on Facility Planning Areas (FPA), which are shown in Figure 1. An FPA is the area recognized by the Illinois Environmental Protection Agency as the planning area for each sanitary district. The FPA may include area beyond that currently served by that provider. FPAs can expand over time, especially on the fringes of development. New FPAs can also be created. Given the metropolitan scope and level of aggregation of this analysis, we ignore these potential adjustments in FPA boundaries.

[Insert Figure 1 about here.]

\section{Initial Situation}

Although we have current flow data for some Facility Planning Areas, we do not have complete data. Therefore, we estimate current flows using these engineering estimates and 1990 population and employment data. We used the conventional estimate of 100 gallons per capita per day (gcpd), which is currently recommended for system design purposes by the Illinois Environmental Protection Agency. These estimates were compared to the flow data for FPAs for which we have data. The computed estimates are, in general, lower than the observed flows. There are several possible explanations. Many of these plants may collect from combined storm and sanitary sewers and through old pipes, which are subject to higher rates of infiltration than assumed for current design standards.

Of 103 FPAs in the Chicago metropolitan region, we have data for 71 . The other 32 are outside of the area covered by the NIPC population and employment forecasts, very 
small in demand and area, or in a few cases missing data. We excluded from the scenarios the Metropolitan Waste Reclamation District of Greater Chicago (MWRDGC) and the forecasted demand for this FPA. These plants are 50 to 100 times larger than most other plants. The 1990 capacity for the MWRDGC is about 2,150 MGD while all others combined are just $500 \mathrm{MGD}$ at the end of the 30 year forecast period. One treatment plant in the MWRDGC has a capacity of over 1,000 MGD and another a capacity of 500 MGD. By our calculations the MWRDGC plants currently have sufficient capacity based on the demand predictions we are using. These predictions may be misleading because combined storm and wastewater sewers in this area may also carry significant quantities of surface water. Most of the MWRDGC area is already built out, so demand is unlikely to increase significantly. Errors in estimates of demand or cost for these plants would completely overwhelm the remaining components of the system. These plants are already so large that they will not be further consolidated. Even if additional capacity is built at the same site, it will likely be equivalent to a new plant without replacing the existing plant.

The simulations locate new households and new employees only on "undeveloped" land. For each FPA, the buildout capacity is calculated by assuming that new population and employees will consume land at the same rate as current population and employees consume developed land in that FPA. Treatment capacity for each FPA is initialized for a simulation run, absorbed as development occurs, and increased when plant expansions occur based on the expansion rules of that scenario. 


\section{Demand}

These scenarios use populations and employees forecasted in 1990 by the Northeastern Illinois Planning Commission (NIPC) for each municipality for 2020. NIPC made two forecasts, one assuming a new airport to the south and one assuming the expansion of the existing O'Hare Airport. We use the forecasts without the new airport. The differences are not pertinent to this investigation of generic strategies, but would be pertinent to decisions to build particular plants. We assume that growth is linear with respect to time and convert the 30 -year forecasts to five year intervals from 1990 through 2020.

These forecasts are also converted spatially from municipalities to FPAs. First, we create the geographic intersection (polygon overlay) of municipalities, facility planning areas, and undeveloped land. Forecasts for each FPA are computed as weighted averages of the forecasts for the municipalities included in the FPA. For each municipality, we compute the proportions of its undeveloped area in each of the FPAs that served any of its area. These portions of each municipality's growth are then summed across municipalities to obtain the growth for the FPA. These calculations yield a population increment and an employment increment for each FPA for each five-year interval.

Treatment plants are designed to handle a daily average flow estimated from the intended service area (see e.g., Viessman and Hammer, 1998). To estimate demand in the same units, we use engineering estimates of daily average flow as a function of population for residential and number of employees for non-residential. Demand as population and employment is converted to demand in Gallons Per Day (GPD) of treatment capacity. The current engineering convention is to use 100 gallons per resident 
per day (see e.g. USGS 2001 at http://ga.water.usgs.gov/edu/navguide.html\#wateruse).

For commercial and industrial employment, we estimated consumption from United States Geological Survey and Illinois Statistical Abstract data, which resulted in 100 gallons per day per employee. This calculation was approximated in a couple of ways. The simplest was to take total water consumption from public supply sources for commercial and industrial uses for Illinois, assume 80 percent of it is returned to wastewater treatment system, rather than being consumed in process or product, and divide this number by the total number of employees in Illinois.

We also computed demand at buildout. Working from NIPC land use data, we computed the amount of developed urban land and the amount of land available for urban development in each FPA. Developed urban land is currently urbanized, which is calculated as all categories except agriculture, vacant, park, wetlands, and water. Land available for urban development is total land minus developed urban land, parks, water, and wetlands, which leaves agriculture and vacant. Buildout demand is computed as remaining available land in the FPA multiplied by the current density of demand in that FPA. The current density of demand is total GPD divided by developed area for that FPA. These buildout estimates are used to set plant sizes in expansion scenarios.

Costs

Costs are calculated after running a simulation to generate an expansion path - a sequence of changes in sizes of treatment plants at five year time intervals. Costs include treatment plan costs, interceptor costs to bring wastewater from sites of existing plants to new consolidated plants, and operating costs. 
The cost of an expansion path for treatment plants is computed as follows:

$$
\operatorname{Cost}=\Sigma_{\mathrm{j}} \Sigma_{\mathrm{t}} \mathrm{PW}_{\mathrm{t}}\left[4.57 \mathrm{Q}_{\mathrm{jt}}{ }^{88}\right]
$$

Where

$$
\begin{array}{ll}
\text { Cost }= & \text { cost in millions of dollars in } 1990 \text { in } 1990 \text { dollars } \\
\mathrm{j}= & \text { treatment plant service area } \\
\mathrm{t}= & \text { time } \\
\mathrm{PW}_{\mathrm{t}}= & \text { present worth function for capital stock investment at beginning of } \\
& \text { interval } \mathrm{t} \\
\mathrm{Q}_{\mathrm{jt}}= & \text { size in million gallons per day design flow of new plant capacity in } \\
& \text { service area } \mathrm{j} \text { put in service at year } \mathrm{t} \text { (the beginning of an interval) }
\end{array}
$$

The capital cost function is from the United States Environmental Protection Agency (1978b), and is converted to 1990 dollars by multiplying the coefficient by the ratio of price indexes. Note that the exponent .88 is close to 1.0 , which means that the economies of scale are relatively small. It is, therefore, not surprising that much of the difference among the scenarios reported below is attributable to differences in timing of replacement of existing capacity, not just to the increase in plant size.

These capital cost calculations assume that a plant gets built once and lasts forever. Under these assumptions, the age of a plant when it is replaced by consolidation would be irrelevant. In practice, treatment plants have limited life spans because components wear out and technologies and standards change. It is, therefore, necessary to account for 
replacement of plants in order to take this timing question into account and to handle differences in salvage value at the end of a time period. The cost calculations were modified to consider an infinite stream of plant replacements at a fixed interval and cost. We assume that the plant must be replaced every thirty years at a cost equal to the cost of construction. Speir and Stephenson (2002) annualized costs over a 30 year life, and the 30 year life and replacement cost assumptions are also roughly consistent with other specific cases of replacement. All existing plants are assumed to be new in 1990. Sensitivity to these assumptions is considered below.

The present cost of construction now and a stream of replacements is the sum of a geometric series

$$
\text { c, c / (1+R), c/ }(1+R)^{2}, \mathrm{c} /(1+\mathrm{R})^{3} \ldots \ldots
$$

where $\mathrm{c}$ is the cost of initial and replacement construction and $\mathrm{R}$ is the discount rate over the interval of replacement. For this geometric progression of costs, with $1 /(1+\mathrm{R})$ less than 1 , the sum can be approximated as $\mathrm{c}(1+\mathrm{R}) / \mathrm{R}$. Thus the equation above can be modified by inserting a coefficient $\mathrm{S}$ equal to $(1+\mathrm{R}) / \mathrm{R}$ for particular instances of $\mathrm{R}$ based on annual discount rate and replacement interval to estimate the cost of building and sustaining through replacement.

$$
\operatorname{Cost}=\Sigma_{\mathrm{j}} \Sigma_{\mathrm{t}} \mathrm{PW}_{\mathrm{t}}\left[\mathrm{S} 4.57 \mathrm{Q}_{\mathrm{jt}}{ }^{88}\right]
$$

Note that the cost is still discounted from the year in which the plant is first constructed. Thus the timing of replacement of capacity during consolidation is still accounted for. In our calculations, any plant that was not replaced within the interval 1990 to 2020 based on expansion path rules of the scenario is replaced in 2020 to account for costs of sustaining that capacity. 
Costs for the interceptors are calculated as a function of pipe length and quantity of flow using estimates from (Nakamura and Brill, 1977) based on (Deininger and Su, 1971; Nakamura and Brill, 1977) and converted to 1990 dollars.

$$
\text { Link Cost }=\mathrm{PW}_{\mathrm{t}}\left(0.864 \mathrm{q}_{\mathrm{jt}}^{0.5} \mathrm{~L}_{\mathrm{j}}\right)
$$

where $\mathrm{q}_{\mathrm{jt}}$ is flow in millions of gallons per day in link $\mathrm{j}$ and $\mathrm{L}_{\mathrm{j}}$ is length of the link in miles. A network of links is designed to bring wastewater from each existing plant to the location of the consolidated plant. This network is sized to handle the buildout or forecasted flows of each plant in the consolidated service area. The interceptor network follows the stream network to assure gravity flow. The cost for this interceptor network is the sum of the costs for each link and is incurred when the consolidated plant is built.

Operating costs must also be considered because they contribute substantially to total costs. The operating cost curve equation is

$$
\text { Operating Cost }=\Sigma_{\mathrm{t}} \mathrm{PW}_{\mathrm{t}}\left(1.78 \mathrm{Q}_{\mathrm{jt}}{ }^{0.96}\right)
$$

where $Q_{j t}$ is daily average flow at time $t$ in plant serving service area $j$. The operating cost function is from the United States Environmental Protection Agency(1978a), and is converted to 1990 dollars. This exponent is even closer to 1.0, meaning that operating costs show even lower economies of scale than capital costs according to these data. Operating costs track flow until year 2020. After 2020 annual operating costs for each plant are constant because flows are assumed to equal forecasted 2020 or buildout, whichever is greater. For operating costs we add the operating costs for the first 30 years to the discounted infinite stream of operating costs from year 30 
These treatment plant capital costs, network costs for interceptors to consolidated plants, and operating costs are used to assess expansion paths. The next section describes three scenarios, which are then compared to assess potential cost savings.

\section{Scenarios}

Three scenarios use different expansion path rules for levels and timing of treatment plant consolidation. The distinctions among the scenarios result only from differences in the expansion rules. Each scenario uses the same initial conditions based on 1990 census data, 1990 plant capacities, and 1990 estimated inflows.

The first scenario is "Local Consolidation." If and when the capacity in an FPA is exceeded, a new plant is built. Its capacity is sufficient to replace existing capacity and to handle in that FPA either buildout demand or the forecasted 2020 demand, whichever is greater. This scenario reduces the number of plants slightly because it computes capital costs as if there were only one plant in each FPA even though some FPAs currently have more than one plant. The costs of interceptors to connect plants within an FPA are small relative to other costs and are ignored. The times at which new capacity is added in the Local Consolidation scenario are shown in Table 1. If no new capacity is shown until the Final column, then a plant is built in 2020 to account for sustainable capacity with a 30 year replacement interval. Capacities in the Final column are sufficient for forecasted 2020 demand, buildout demand, or initial plant capacity, whichever is greater. The total capacity is then 494.97 MGD. The 2020 capacities were also calculated as 2020 demand or buildout, which yields the total shown in parenthesis, 291.49. This total is lower 
because it does not build plants to equal initial capacity where that exceeds predicted demand, and there is significant initial excess capacity.

[Insert Table 1 about here.]

The second and third scenarios, "Late Consolidation" and "Early Consolidation", use an exogenously determined regionalization into four treatment plants serving the major watersheds shown in Figure 1. These regional consolidations include 51 FPAs because the other 20 FPAs were for various reasons difficult to connect to regional plants. These 20 remain separate as in Scenario 1. Early Consolidation addresses economies of scale by closing more small plants and closing them sooner than Late Consolidation. Early Consolidation, however, builds large plants that will be underutilized for longer periods of time and replaces more existing plants before the end of their useful lives.

In Late Consolidation, if and when the capacities of all FPAs in a major watershed are exceeded, a new regional plant is built. Its capacity handles predicted 2020 or buildout demand, whichever is greater, for the entire major watershed. This scenario relies on shifting forecasted population and employment growth among FPAs within each major watershed to use available capacity until all capacity in the watershed is used. For Late Consolidation, by assuming use of a very small amount of available MWRDGC capacity in the last decade, existing capacity is sufficient to absorb forecasted growth in each major watershed. Thus, no new plants are built until 2020 when replacement is required. The same four regional plants are built as in Early Consolidation, but at a later time. These four plants are the same sizes as for the Early Consolidation scenario shown in Table 2.

[Insert Table 2 about here.] 
In "Early Consolidation", if and when the capacity of any one FPA in a major watershed is exceeded, a new regional plant. Its capacity handles all existing demand and additional demand to buildout or 2020 forecast, whichever is greater, for the entire watershed. In both these scenarios existing plants are closed and connected by interceptors to the new consolidated plant as soon as it is built. Early Consolidation results are shown in Table 2.

Table 3 compares costs for the three scenarios. The capital costs are net present value in 1990 in 1990 dollars for plant construction and replacement for an infinite horizon. The operating costs include the first 30 years plus an infinite horizon with constant plant size from 2020. The interceptor costs are construction costs for those interceptors necessary for plant consolidations and replacement on a 50 year interval.

[Insert Table 3 about here.]

The capital cost numbers in parentheses in Table 3 assume that final capacities are built equal to or greater than initial capacities for all FPAs in Local Consolidation and the FPAs not part of the regional consolidations for the Late and Early Consolidation scenarios. These capital costs are thus higher. The order of preference remains the same, but costs for Local Consolidation are comparatively higher because initial capacities apply to all FPAs. The number in parentheses for Local Consolidation might be more realistic, recognizing the incentive for individual FPAs to build large plants to gain growth in competition with neighbors.

Local Consolidation within FPAs implies some consolidation because plant costs are based on the entire FPA, even if it currently has more than one plant. Network 
consolidation costs in these cases are not reported because they will be much smaller than for consolidation across FPAs for a major watershed. This scenario represents the level of consolidation that could be accomplished within existing FPA jurisdictions.

Late Consolidation builds no new plants until replacements in 2020. Late consolidation has the lowest capital costs because new plant construction is delayed for 30 years. Late consolidation has slightly higher operating costs than Early Consolidation however, because it continues to rely on many small plants for the first 30 years. It also is the only scenario that requires shifting population and employment from the forecasted locations in order to use existing capacity. It thus incurs higher costs of planning, incentives, and regulations, which are not included in these estimates.

In Early Consolidation, it is expensive to regionalize into large plants as soon as capacity of any one FPA in the watershed is exceeded because the new plant replaces all existing capacity. That is, it builds a new plant to handle the entire major watershed, and all other existing capacity in the watershed is shut down. It also creates buildout or 2020 capacity long before it is needed. Capital costs are thus much higher than for Late Consolidation and even higher than for Local Consolidation, despite the smaller number ofplants and larger plants in Early Consolidation. Operating costs are lower for Early Consolidation because two large plants are built in the first period and another in 2010 . As shown in Table 4, Early Consolidation saves operating costs in the first 30 years but is the same as Late Consolidation after that.

[Insert Table 4 about here]. 


\section{Sensitivity to Assumptions and Data}

How might assumptions and uncertainty in data values affect the interpretation of these results? It is worth planning for urban development in relation to economies of scale for infrastructure if and only if some expansion strategies have an advantage over others and these advantages are large enough to compensate the costs of using that strategy. Not only the order of preference, but also the magnitudes of differences among the scenarios matter. This section considers possible effects on order of preference and magnitudes of differences of several assumptions and data items.

Single case study. Chicago is unusual in having such a large number of existing plants and thus presents a particularly valuable case. If, in this case, magnitudes of differences among strategies were not large enough to justify intervention, then planning for investments and regulations is unlikely to be useful in other metropolitan areas in which treatment plants are already more consolidated. If, on the other hand, intervention is justified here, then when other metropolitan areas grow to encompass existing treatment plants in surrounding small towns, similar strategies might be applicable.

Population forecasts. A larger total population and employment would increase the magnitude of savings from consolidation because it would increase the size of consolidated plants, which have a relative advantage over smaller sized plants. The spatial pattern of population growth relative to capacities of existing plants could matter, as demonstrated by the difference between Late Consolidation, which relies on shifting population and employment to fit available demand, and Early Consolidation, which accommodates forecasted population and employment in place. If the forecast happened to put the population and employment in the "right" places, there would be no gain from 
redirecting it and thus no benefit from trying to do so. In this case, there are potential gains, which may be sufficient to justify the costs.

Demand coefficients. There is uncertainty as to appropriate coefficients of demand per person and per employee. Variation in these is equivalent to variation in the population or employee forecasts. Our calculated estimates for 1990 demand were lower than observed flows. Increasing the demand coefficients would yield greater savings from consolidation. The same spatial effects discussed for population could also occur. Increased demand sufficient to require that plants be built sooner would, however, decrease the advantage of Late Consolidation over Early Consolidation.

Initial plant capacities relative to 1990 demand. Uncertainty in initial plant capacities arises because of lack of data on current flows and differences between observed flows that may include large percentages of infiltration and storm water compared to design standards used for new systems. When design standard coefficients were used with initial populations and employments for 1990, the estimates for inflow to existing plants were less than reported inflows for most plants for which we have data. If demand should be based on higher coefficients to account for old pipe systems with high inflows or storm drainage entering the sanitary sewer system, then plant capacities would be exceeded sooner and bigger plants would be built. The advantages of consolidation would therefore be greater. The results presented here may thus underestimate the benefits of consolidation.

Remaining service life of existing plants. In the simulations, all existing plants are assumed to have 30 years of remaining useful life. The Late Consolidation scenario gains advantage in part because it avoids replacing usable capacity before the end of its 
useful life. It builds all replacement and needed capacity in 2020 which is equivalent to building all new capacity after reaching buildout. The other scenarios build new consolidated plants when capacity of one plant is exceeded and, therefore, also replace many plants with remaining useful service life. If existing plants had a uniform distribution of remaining life from zero to 30 years, the advantage of Late Consolidation would decrease because some of the existing plants would have to be replaced sooner whether or not their capacity was exceeded. The assumption that all plants have 30 years of remaining life may lead to an overestimate of the difference between Early and Late consolidation.

Replacement interval or replacement cost. The replacement cycle solves the problem of comparing scenarios that end with different capacities at different service life ages. It introduces other uncertainty, however, about the replacement interval and replacement cost. These two variables can be treated as if they were one because varying the replacement cost is equivalent to varying the replacement interval once the present value is computed. The 30-year replacement interval and construction cost as replacement cost are both probably pessimistic. That is, the interval is probably longer in practice because infrastructure is seldom maintained to standards advocated by engineers. Some of the existing facility is likely to be reusable so that replacement costs may be less than initial construction costs. On the other hand, modification and remodeling may be more expensive per unit of capacity than new construction. These sustainability costs are constant for each scenario after 2020 and thus depend only on the 2020 configuration of plants. If costs based on a 30 year interval and using initial cost as replacement cost are high, then they overstate the magnitude of advantages of consolidation 
Discount rates. Discount rates used to compute present value or annualize capital costs can affect order of preference and will affect magnitudes of difference as shown in Table 5. A lower discount rate increases the effect of future costs as a component of total costs. The lower the discount rate, the greater the advantage of consolidation because consolidation yields continuing advantage far in the future. A lower discount rate also decreases the advantage of Late Consolidation because it reduces the advantage from spending money later. A low discount rate favors consolidation but not later construction. The results in Table 5 suggest, however, that timing is still crucial in yielding differences among the scenarios.

Economies of scale exponent parameters for construction costs. The economies of scale exponent of .88 for construction cost is relatively close to 1.0 and thus suggests little economy of scale. Greater economies of scale (a lower value) would advantage consolidation and vice versa. We have no reason to believe that this exponent is either high or low, so we cannot predict the likely direction or magnitude of error.

Economies of scale exponent parameters for operating costs. The economies of scale exponent for operating costs of .96 is very close to 1.0 , suggesting almost no economies of scale. The conventional wisdom is that large plants yield significant economies of scale in operation because of the need for an operator for modern plants. This effect may be greatest for a range of relatively small plant sizes, but be overpowered by materials and energy costs for differences among very large plants. Again, we have no basis for judging this to be a low or high estimate and thus no basis for direction of error. If operating economies of scale were greater (smaller number), not only would consolidation be advantaged but also Early Consolidation. 
Replacement versus increments of plant size. In building new plants, our calculations assume that existing capacity is replaced, that is that the cost of the new plant is based on the total size of the new plant, not the increment. For Late and Early Consolidation, the consolidated plants are so much larger than the existing plants at their locations that it is likely an entirely new plant would be constructed. Also, when expansions occur, renovations of existing capacity are likely to be accomplished jointly, which we are approximating as equal to initial construction cost. This approach may overestimate the advantages of consolidation because costs are lower than if costs for the existing plant and a new plant for the added increment were computed separately. Given that the existing plants are generally small relative to the added capacity, the difference from treating them as one plant should also be small.

Perception effects of expressing results in present value versus annualized costs. In thinking about whether a difference among scenarios is large enough to justify intervention, expressing differences in present value rather than annualized value may matter. People may have different reactions to what is "large" enough to justify intervention. For an infinite horizon at $5 \%$ discount rate, the annual equivalent is obtained by dividing by 20 . Thus the $\$ 170$ million difference in capital costs is equivalent to $\$ 8.5$ million annually. This still seems large enough to make intervention alternatives worth considering.

\section{Implications for Infrastructure Planning and Metropolitan Development}

Consolidation strategies for Metropolitan Chicago that replace very little existing capacity before the end of its useful life, such as the Late Consolidation scenario, might save on the order of $\$ 170$ million in capital costs and \$20 million in operating costs when 
compared to Local Consolidation. The Late Consolidation scenario is achieved in the simulations by shifting forecasted population and employment to other FPAs within the major watershed that have available capacity until all available capacity in the major watershed is used. These results suggest that at the metropolitan scope, the conventional wisdom is correct: Savings can be achieved by allowing development only where capacity is available. This scenario would be difficult to accomplish, however, with current patterns of multiple jurisdictions, local control, and competition for real estate tax base and retail sales tax among jurisdictions.

Another way to think about these results is that consolidation can occur after buildout. After an area is completely built out and at a time when a large portion of the existing capacity in a major watershed is nearing the end of its useful life, it will be worth building a consolidated plant. This strategy could be implemented by stretching the life of some plants so that it made sense to replace all or most of the capacity at once. The long term savings will be sufficient to justify consolidation if only a small proportion of replaced capacity has remaining useful life. If buildout has already occurred, there is also less interjurisdictional competition for new capacity in particular areas at particular times because the tax generating activities are already in place and treatment plant consolidation will not affect their location choice criteria. Consolidation could then occur at an appropriate time without requiring that demand be shifted from one area to another, thus reducing the costs of intervention through incentives and regulation.

The conventional wisdom is that urban development can be more efficient by relying on infrastructure investments of efficient size with respect to economies of scale and using available capacity before building new capacity. Our results are consistent with 
these principles, but they highlight the difficulties that arise when development does not start from a clean slate and demand is dispersed across a large area. The efficient sizes of treatment plants can be so large that few regions will ever grow fast enough to justify building efficiently sized plants for increments of growth as growth is occurring. Forcing development to locate so as to use available capacity can yield large gross savings. In some cases, shifting demand may be too difficult to achieve to justify even these large savings. The economies of scale for treatment plants must also complement other infrastructure with different economies of scale and different spatial patterns. Thus gains from efficient provision of treatment plants are likely to conflict with gains for other infrastructure. Resulting tradeoffs will reduce the possible gains from careful timing and demand shifting for treatment plant provision.

\section{Conclusion}

The potential gains for treatment plants would be much easier to realize after buildout has occurred because conflicts in timing with other infrastructure and difficulties of redirecting new development to available capacity would be largely eliminated. It is thus likely that in many situations it will be more productive to plan for growth with a mix of small treatment plants while growth occurs and then make major consolidations after buildout occurs. Even in this approach, it is crucial to consider the remaining useful life of plants to be replaced by consolidation. This approach may be consistent with what has happened historically in many metropolitan areas.

This approach does not mean that plans linking infrastructure and land use are not useful. It means that plans should not only focus on chunks of development as they 
occur, but also account for very long term consolidation scenarios. Plans as strategies should consider that some treatment plants and sites will be used for only short periods of time, that needed additional land area in eventual consolidation locations should be identified and reserved, that plants later abandoned will require that new interceptors be built for which rights of way should be identified and reserved, and that jurisdictional consolidations and cooperation should be expected to change over time as development occurs.

\section{References}

Bahl R W, Jr., 1963, A Bluegrass Leapfrog Lexington, Bureau of Business Research, University of Kentucky

Burchell R W, Shad N A, Listokin D, Philliips H, Downs A, Seskin S, Davis J S, Moore T, Helton D, Gall M, 1998, The Costs of Sprawl -- Revisited Washington, D.C., Transportation Research Board

Chang S-Y, Brill E D, Jr., Hopkins L D, 1982, "Use of Mathematical Models to Generate Alternative Solutions to Water Resources Planning Problems", Water Resources Research 18 58-64 
Deininger R A, Su S Y, 1971. Regional Wastewater Treatment Systems, The Institute of Management Science National Conference, Washington, D. C.

Frank J E, Fulconer M K, 1990, "The Measurement of Capacity: Theory, Data Structure, and Analytics", Computers, Environment, and Urban Systems 14 283-297

Freidenfelds J, 1981, Capacity Expansion: Analysis of Simple Models with Applications (Elsevier North Holland, Inc., Amsterdam)

Hopkins L D, 2001a, Should additional land be serviced for urban development? When? Where? How much? In Land supply and infrastructure monitoring for smart urban growth Ed. G J Knaap. (Lincoln Institute of Land Policy, Cambridge, MA)

Hopkins L D, 2001b, Urban development: The logic of making plans (Island Press, Washington, DC)

Kaiser E J, Godschalk D R, Chapin F S J, 1995, Urban Land Use Planning (University of Illinois Press, Urbana, Illinois)

Knaap G J, Ding C, Hopkins L D, 2001, "Managing Urban Growth for the Efficient Use of Public Infrastructure: Toward a Theory of Concurrency", International Regional Science Review 24 328-343 
Nakamura M, Brill E D, Jr., 1977, Mathematical Methods for Use in Planning Regional Wastewater Treatment Systems Urbana, Illinois, University of Illinois Water Resources Center

Peiser R B, 1984, "Does it Pay to Plan Suburban Growth?" Journal of the American Planning Association $\mathbf{5 0}$ 419-433

Segoe and Associates L, 1958, Master Plan Supplement: City-County Planning and Zoning Commission of Lexington and Fayette County, Kentucky Cincinnati, Ohio

Speir C, Stephenson K, 2002, "Does Sprawl Cost Us All? Isolating the Effects of Housing Paterns on Public Water and Sewer Costs", Journal of the American Planning Association 68 56-70

United States Environmental Protection Agency, 1978a, Analysis of Operation and Maintenance Costs for Municipal Wastewater Treatment Systems Washington. DC, United States Environmental Protection Agency 
United States Environmental Protection Agency, 1978b, Construction Costs for

Municipal Wastewater Treatment Plants: 1973-1977 Washington, DC, United

States Environmental Protection Agency

Viessman W J, Hammer M J, 1998, Water Supply and Pollution Control (Addison-

Wesley Longman, Inc., Menlo Park, CA)

Windsor D, 1979, "A Critique of the Costs of Sprawl", Journal of the American Planning

Association 45 279-292 
Table 1 New construction and final capacities for Local Consolidation Scenario

\begin{tabular}{|c|c|c|c|c|c|c|c|c|}
\hline FPA Name & 1990 & 1995 & 2000 & 2005 & 2010 & 2015 & 2020 & Final \\
\hline Addison & & & & & & & & 8.50 \\
\hline Algonquin & & & & & & 2.85 & & 2.85 \\
\hline Antioch & & & & & & & & 1.60 \\
\hline Aurora & & & & & & & & 42.00 \\
\hline Barrington & 5.78 & & & & & & & 5.78 \\
\hline Bartlett & & & & & & & & 4.88 \\
\hline Batavia & & & & & & 4.04 & & 4.04 \\
\hline Beecher & & & & 1.00 & & & & 1.00 \\
\hline Bensenville & & & & 5.10 & & & & 5.10 \\
\hline Bonnie Brae/Forest Man & 0.33 & & & & & & & 0.33 \\
\hline Braidwood & & & & & & & & 0.63 \\
\hline Carol Stream & & & & & & & 5.78 & 5.78 \\
\hline Carpentersville & & & & & & & & 5.00 \\
\hline Cary & & & & & & & & 3.25 \\
\hline Citizen's Utilities Co. & & & & & & & & 5.04 \\
\hline Crest Hill & & & & & & 1.99 & & 1.99 \\
\hline Crystal Lake & & & & & & & & 6.20 \\
\hline Deerfield & & & & & & & & 8.00 \\
\hline East Bolingbrook & 2.55 & & & & & & & 2.55 \\
\hline East Dundee & & & & & & & & 1.15 \\
\hline Elburn & & & & & & & & 1.27 \\
\hline Elmhurst & & & & & & & & 8.00 \\
\hline Elwood & & & & & & & 0.54 & 0.54 \\
\hline Frankfort & & & & & & 4.90 & & 4.90 \\
\hline FRWRD & & & & & & & & 34.35 \\
\hline Geneva & & & & & & & & 4.00 \\
\hline Gilberts & & & & & & & & 0.80 \\
\hline Glendale Hts & & & & & & & & 8.71 \\
\hline Hampshire & & & & & & & & 0.46 \\
\hline Hanover Park & & & & & & & & 3.82 \\
\hline Harvard & & & & & & & 2.64 & 2.64 \\
\hline Hebron & & & & & & & 0.66 & 0.66 \\
\hline Huntley & & & & & 3.46 & & & 3.46 \\
\hline Island Lake & & & & & & & & 1.20 \\
\hline Itasca & & & & 4.81 & & & & 4.81 \\
\hline Joliet & & & & & & & & 19.50 \\
\hline Lake in the Hills & & & & & & & & 3.10 \\
\hline Lake Zurich sub SE Lake & 2.70 & & & & & & & 2.70 \\
\hline
\end{tabular}




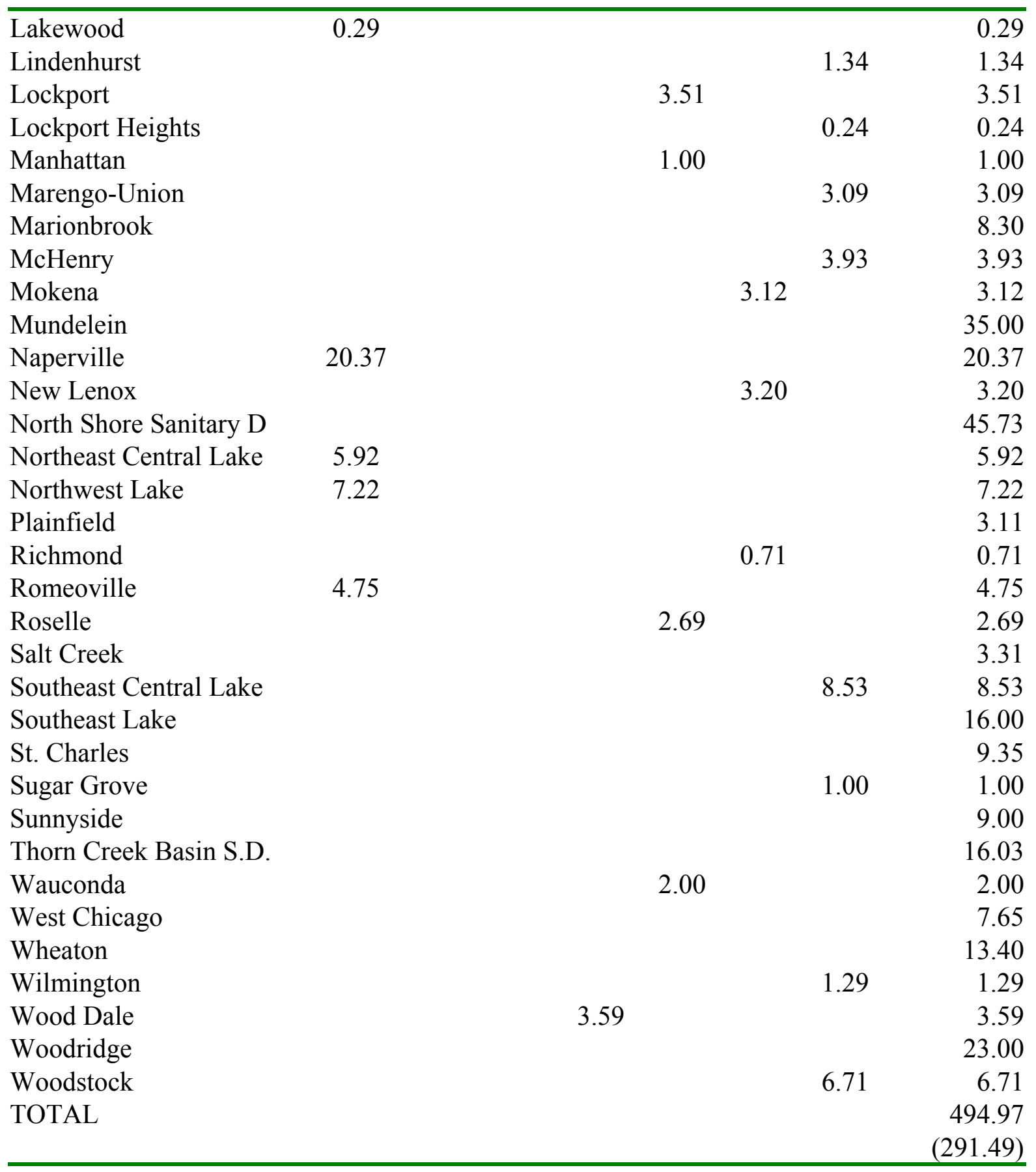


Table 2 New construction and final capacities in Millions of Gallons per day for Early Consolidation Scenario

\begin{tabular}{|c|c|c|c|c|c|}
\hline Watershed & 199019952000 & 2005 & 2010 & 20152020 & Final \\
\hline Skokie/Des Plaines & 85.74 & & & & 85.74 \\
\hline Fox & 63.16 & & & & 63.16 \\
\hline Illinois & & & 79.91 & & 79.91 \\
\hline Kishwaukee & & & & 9.80 & 9.80 \\
\hline Unconsolidated FPAs & 30.99 & 1.00 & 3.46 & 1.9914 .15 & 51.69 \\
\hline Total & & & & & 290.30 \\
\hline
\end{tabular}


Table 3 Comparison of Scenarios in millions of dollars

\begin{tabular}{|c|c|c|c|}
\hline & $\begin{array}{c}\text { Local } \\
\text { Replacement }\end{array}$ & $\begin{array}{c}\text { Late } \\
\text { Consolidation }\end{array}$ & $\begin{array}{c}\text { Early } \\
\text { Consolidation }\end{array}$ \\
\hline Capital Cost (5\%) & $\begin{array}{r}549 \\
(742)\end{array}$ & $\begin{array}{r}379 \\
(431)\end{array}$ & $\begin{array}{r}820 \\
(873)\end{array}$ \\
\hline Operating Cost & 730 & 710 & 676 \\
\hline Interceptor Cost & 0 & 24 & 77 \\
\hline Total Cost & 1279 & 1113 & 1573 \\
\hline
\end{tabular}


Table 4 Timing of operating costs in millions of dollars

\begin{tabular}{cccc}
\hline & $\begin{array}{c}\text { Local } \\
\text { Replacement }\end{array}$ & $\begin{array}{c}\text { Late } \\
\text { Consolidation }\end{array}$ & $\begin{array}{c}\text { Early } \\
\text { Consolidation }\end{array}$ \\
\hline $\begin{array}{c}\text { Operating Cost in } \\
\text { 30 years (5\%) }\end{array}$ & 516 & 516 & 482 \\
Infinite Horizon & 214 & 194 & 194 \\
Total & 730 & 710 & 676 \\
\hline
\end{tabular}


Table 5 Sensitivity of treatment plant construction costs to discount rates in millions of

$$
\text { dollars }
$$

\begin{tabular}{lccc}
\hline & $\begin{array}{c}\text { Local } \\
\text { Replacement }\end{array}$ & $\begin{array}{c}\text { Late } \\
\text { Consolidation }\end{array}$ & $\begin{array}{c}\text { Early } \\
\text { Consolidation }\end{array}$ \\
\hline $\begin{array}{l}\text { Capital Cost } \\
(2 \%)\end{array}$ & 1,583 & 839 & 1,103 \\
$\begin{array}{l}\text { Capital Cost } \\
(5 \%)\end{array}$ & 549 & 379 & 820 \\
$\begin{array}{l}\text { Capital Cost } \\
(8 \%)\end{array}$ & 332 & 264 & 730 \\
\hline
\end{tabular}



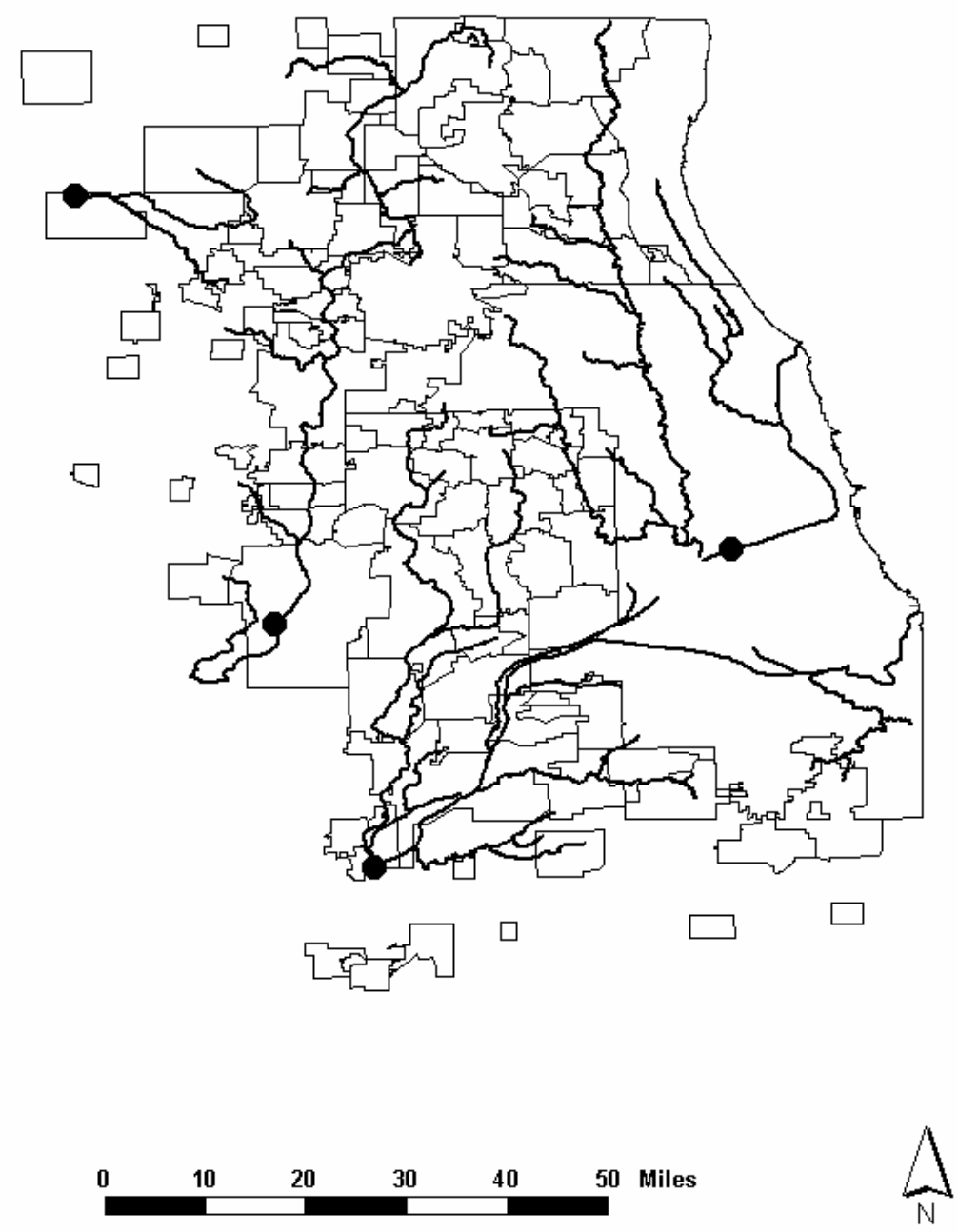

Figure 1 Chicago Region FPAS, major watersheds, and consolidated plant locations 